\title{
NUTRITION AND THE EYE
}

\author{
${ }^{*}$ E. T. lyasele, ${ }^{*}$ A. B. Akpe.
}

*Department of Ophthalmology, University of Benin Teaching Hospital Benin City, Nigeria.

\section{Correspondence:}

Dr E. T. lyasele

Department of Ophthalmology, University of Benin Teaching Hospital

Benin City, Nigeria.

Email: efenchi@yahoo.ca

\section{ABSTRACT}

Objective: To review ocular pathology associated with poor nutrition and highlight nutrients necessary for healthy eyes

Method: Information obtained through review of literature in a pubmed/medline search using the words nutrition, eye, disease; journals, review articles and textbooks.

Results: Nutritional deficiencies can lead to ocular diseases such as Xerophthalmia (Vitamin A deficiency) and nutritional optic neuropathy. Poor nutrition has been implicated in the pathogenesis of cataracts and age related macular degeneration. Good nutrition thus helps in preventing and retarding progression of several diseases.

Conclusion: It is advisable to pay attention to what we eat and increase our intake of fruits, vegetables and fish for healthy eyes.

Key words: nutrition, eye, nutritional deficiency, supplements.

\section{INTRODUCTION}

"You are what you eat" is an adage which underscores the emphasis that has and is still being placed on healthy nutrition. Several studies have shown that foods eaten or not eaten have a profound effect on health ${ }^{1-4}$.
The eye can be regarded as the window for the body as the effect of several systemic diseases can be seen in eye before they have a significant detrimental effect on other parts of the body. These include diabetes, vitamin A deficiency, hypertension and HIV infection to mention a few.

Nutrients are classified as essential or non essential. Non essential nutrients are manufactured in the body and do not need to be obtained from food. Examples include cholesterol which is present in all animal cells ${ }^{1}$. Essential nutrients must be obtained from food sources, because the body either does not produce them or produces them in amounts too small to maintain growth and health. Essential nutrients include water, carbohydrates, proteins, fats, vitamins, and minerals

This article discusses some eye diseases which have been linked with poor nutrition, as well as the nutrients and diet necessary for healthy eyes.

These diseases include vitamin A deficiency, cataracts, age related macular degeneration and dry eyes. Some nutrients have also been found helpful in the treatment of glaucoma and diabetic retinopathy ${ }^{5}$. 
XEROPHTHALMIA

Vitamin $A$ is essential for the synthesis of retinal photopigment-rhodopsin and conjunctival glycoproteins ${ }^{6}$. It is essential for immunity as well as maintainance of health of mucous membranes $^{7}$. Deficiency also leads to susceptibility to respiratory, intestinal and genitourinary infections. The retinal pigment epithelium plays a major role in the metabolism and storage of Vitamin $A$ and is second only to the liver in the concentration of Vitamin $A^{6}$.

Xerophthalmia is a spectrum of ocular disease caused by vitamin $A$ deficiency and is responsible for 100,000 new cases of blindness worldwide each year especially in developing countries $^{8}$. Vitamin A deficiency (VAD) is the commonest single cause of blindness in children, accounting for an estimated 350,000 new cases each year ${ }^{9}$. Vitamin A deficiency is also very important as it is associated with higher infant and childhood mortality rates, particularly associated with measles. While vitamin A deficiency can occur at any age, the group at risk of blindness is children in the preschool age group, from 6 months to 6 years of age especially if their mothers had VAD in pregnancy or during breastfeeding ${ }^{9}$.

Vitamin A deficiency can occur for three major reasons:
- Reduced intake of foods rich in vitamin A

- Poor intestinal absorption of vitamin $A$, usually because of diarrhoea

- Increased need for vitamin A, as occurs during infections, especially measles, herpes simplex, malaria.

\section{WHO GRADING OF XEROPHTHALMIA (Table I)}

Clinical features include night blindness (nyctalopia), ocular irritation due to dryness and Bitot spots which are triangular patches of keratinized epithelium in the palpebral zone associated with infection by Corynebacterium xerosis ${ }^{8}$. There is a loss of goblet cells of the conjunctiva with squamous metaplasia and keratinzation. The cornea has a lustreless appearance due to dryness, punctuate epithelial erosions which can progress to corneal ulceration ${ }^{8}$. Sterile melting by liquefactive necrosiskeratomalacia may result in perforation of the globe and blindness. The onset is often sudden, as the cornea may melt very quickly, even over a few hours ${ }^{10,11}$. The significant end stage of malnutrition causing eye damage, in a child who survives, is corneal scarring. Corneal scarring often has a marked effect on vision. The anterior part of the eye may bulge forward (anterior staphyloma $)^{10}$.

Table I: WHO GRADING OF XEROPHTHALMIA ${ }^{35}$

\begin{tabular}{ll}
\hline XN & Night blindness \\
X1A & $\begin{array}{l}\text { Conjunctival xerosis } \\
\text { X1B with Bitot's spot }\end{array}$ \\
X2 & Corneal xerosis \\
X3A & Corneal ulceration affecting less than $1 / 3$ corneal surface \\
X3B & $\begin{array}{l}\text { Corneal ulceration/Keratomalacia affecting more than } 1 / 3 \\
\text { corneal surface }\end{array}$ \\
XS & Corneal scar due to xerophthalmia \\
XF & Xerophthalmic Fundus \\
\hline
\end{tabular}




\section{TREATMENT}

Recommended dosages of vitamin A as seen in Table 2

Pregnant women with VAD should have 10.000 I.U of vitamin $A$ as large doses are teratogenic. After giving birth they can be treated with $300,0001 . U$. Vitamin A days 1, 2 and 8 to ensure a good supply of vitamin $A$ in breast milk ${ }^{1,8,10}$.

Intense lubrication with artificial tears and antibiotic ointments and topical retinol to promote healing are helpful.
The child may need corneal transplant (keratoplasty) to treat perforation or corneal scar ${ }^{8}$.

Foods which are rich in vitamin $A$ include palm oil, liver, milk; dark green leafy vegetables, spinach, sweet potatoes, peppers and coloured fruits like pawpaw, mango, carrots contain beta carotene which is a source of vitamin $A$. They should not be overcooked or sun dried ${ }^{11}$.

Table II: THE RECOMMENDED DOSES OF VITAMIN A $^{36}$

\begin{tabular}{|c|c|c|c|c|}
\hline $\begin{array}{l}\text { Emergency } \\
\text { Treatment of } \\
\text { Xerophthalmia }\end{array}$ & & $\begin{array}{l}\text { Dose by } \\
\text { mouth iu }\end{array}$ & $\begin{array}{l}\text { Dose by } \\
\text { mouth mg }\end{array}$ & \\
\hline & Day 1 & 200,000 & 110 & $\begin{array}{l}\text { Children }<1 \mathrm{yr} \\
\text { or } 8 \mathrm{~kg} \text { should } \\
\text { have half dose }\end{array}$ \\
\hline & Day 2 & 200,000 & 110 & \\
\hline & Day 14 & 200,000 & 110 & \\
\hline $\begin{array}{l}\text { Preventive } \\
\text { treatment }\end{array}$ & & & & \\
\hline & Children $<1 \mathrm{yr}$ & 100,000 & 55 & $\begin{array}{l}\text { Repeat every } \\
4-6 \text { months }\end{array}$ \\
\hline & Children >1yr & 200,000 & 110 & $\begin{array}{l}\text { Repeat every } \\
4-6 \text { months }\end{array}$ \\
\hline & $\begin{array}{l}\text { Children at } \\
\text { birth }\end{array}$ & 50,000 & 27.5 & \\
\hline & $\begin{array}{l}\text { Mothers just } \\
\text { giving birth }\end{array}$ & 300,000 & 165 & \\
\hline & $\begin{array}{l}\text { Pregnant and } \\
\text { lactating } \\
\text { mothers }\end{array}$ & 10,000 & 5.5 & $\begin{array}{l}\text { Daily for } 2 \\
\text { weeks }\end{array}$ \\
\hline
\end{tabular}

\section{CATARACTS}

The Nigerian blindness survey conducted between 2004 and 2007 revealed that prevalence of blindness for all ages in Nigeria is $0.78 \%$ while prevalence in adults 40 and above is $4.2 \%$. The most common cause of blindness in Nigeria is cataract which accounts for $42.9 \%{ }^{12}$.

A cataract is an opacification of the crystalline lens. The lens is a biconvex avascular transparent structure enclosed by a capsule which helps to bend light rays and focus them on the retina. The lens is made up of several proteins called crystallins, lipids and cytoskeletal elements precisely arranged to maintain transparency. However with time oxidation of side chains, glycation, phosphorylation, carbamylation occur causing 
crosslinking, protein aggregation and increase in pigmentation. These processes cause a loss of transparency and cataract ${ }^{13}$.

There are several factors that we cannot control that may increase the risk of developing cataracts like increasing age, family history and sex $^{14}$. Others however are modifiable for example not smoking, reducing exposure to sunlight by wearing protective eyewear which has filters for ultraviolet (UV) A/B rays and wide brimmed hats, controlling other diseases such as diabetes and eating a healthy diet ${ }^{15}$.

Higher intake of carbohydrates and higher dietary glycemic index (dGI) were associated with higher incidence of nuclear and cortical cataracts ${ }^{16}$.

The lens has a natural antioxidant called gluthathione. Studies have shown antioxidants have a significant role in preventing and are also thought to slow the progression of cataracts $^{17,18}$. These include vitamins $\mathrm{C}, \mathrm{E}$, carotenoids such as lutein and zeaxanthin. The five year follow up to the Beaver Dam Eye Study showed a reduced risk for nuclear and cortical cataracts among people using multivitamins or any supplement containing vitamins $C$ and $E^{17}$. Those with the highest intake of lutein and zeaxanthin had significantly lower risk of developing cataracts ${ }^{17,18}$. Lutein and zeaxanthin are pigments found within the eye in the lens, retina and macular. They help to prevent the effects of UV radiation.

Good sources for vitamin E include almonds, peanuts, corn oil and sunflower seeds while good sources of vitamin C include oranges, grapefruit, tangerines, pawpaw, green pepper, tomatoes.

Dark green leafy vegetables are the primary source of lutein and zeaxanthin, but they are also present in lesser amounts in other coloured fruits and vegetables, such as broccoli, orange peppers, corn, peas, and tangerines.

People taking vitamin $\mathrm{C}$ supplements for more than 10 years had a $45-77 \%$ lower risk of early lens opacities (cataracts) and $83 \%$ lower risk of moderate lens opacities. The higher the serum levels of vitamin $C$, the lower the risk of cataracts ${ }^{19}$. Dietary intake of protein, vitamins $A, C, E$, and carotene, niacin, riboflavin, and thiamine have been found to significantly decrease the risk of all types of cataract ${ }^{20,21}$.

Glutathione (found in asparagus) has been found to be beneficial in delaying progression of cataracts.

\section{AGE RELATED MACULAR DEGENERATION}

This is the most common cause of irreversible blindness in the developed world in people above 50 years of age $^{8}$. Age related maculopathy is like an exaggeration of the ageing process and is characterised by discrete yellow spot (drusen) at the macula and hyper or hypo pigmentation of the retinal pigment epithelium ${ }^{8}$.

Age related macular degeneration (AMD) is more advanced and sight threatening with geographic atrophy, pigment epithelial detatchment (PED), subretinal or retinal pigment epithelium (RPE) haemorrhage and exudates, choroidal neovascularisation and fibroglial scar tissue. Results from the Age related Eye Disease study (AREDS) showed that a combination of high levels of antioxidant vitamins $A$, $C$ and $E$ (in combination with the mineral zinc) significantly reduces the risk of advanced macular degeneration and its associated visual loss ${ }^{23}$.

Recommended doses are ar-24 $^{22}$

- Vitamin C - $500 \mathrm{mg}$

- Vitamin E - $400 \mathrm{IU}$

- Vitamin A (as beta-carotene) $15 \mathrm{mg}$ 
- Zinc (as zinc oxide) - 80 mg

- Copper (as cupric oxide) - 2 mg

- Lutein is also found to be protective. People who had diets rich in green leafy vegetables had reduced risk of developing $\mathrm{AMD}^{25}$.

Consumption of a diet rich in docosahexaenoic acid (DHA) was associated with lower progression of early AMD. In addition to the AREDS recommended supplement, lower dGI with higher intakes of DHA and eicosapntaenoic acid (EPA), was associated with reduced progression to advanced $\mathrm{AMD}^{22}$. These omega 3 fatty acids are also helpful in treatment of dry eyes and prevention of cataracts.

People who smoke should not take supplements containing beta carotene as this has been associated with a higher risk of lung cancer. Natural sources of Beta carotene do not seem to confer increased risk ${ }^{24}$.

\section{GLAUCOMA}

Glaucoma is a group of optic neuropathies with a characteristic optic nerve head cupping and visual field defects with raised intraocular pressure as a major risk factor. The role of nutritional supplements in glaucoma is still being debated. While intraocular pressure is the major modifiable risk factor, some patients have glaucoma progression despite statistically normal intraocular pressures. Some studies have shown that vitamins E, C, B12, gluthathione, alpha lipoic acid, magnesium, thiamine, ginko biloba (a plant extract) have a neuroprotective effect and are helpful in the treatment of glaucoma $^{5,26-28}$.

\section{TOXIC/NUTRITIONAL} NEUROPATHY

OPTIC

Some substances taken into the body can act as exogenous poisons which damage the optic nerve leading to loss of vision. These include heavy alcohol intake, cigarette and tobacco pipe smoking. They act synergistically hence the name Tobacco-Alcohol Amblyopia.

Chronic alcoholics derive calories from breakdown of alcohol, thus neglecting their diet and developing deficiency of proteins and B complex vitamins which are vital to the health of the optic nerve. Cheap adulterated alcohol (local gin-“Ogogoro") has a high content of methyl alcohol which is oxidised in the body to formic acid and formaldehyde which are toxic to the optic nerve ${ }^{30}$.

Some species of cassava have high content of cyanide.If these are processed in a hurry into garri or fufu without removal of the cyanide can lead to optic nerve damage ${ }^{29}$.

Vitamin B complex deficiency can lead to optic atrophy through demyelination of the nerves ${ }^{30}$.

Treatment includes cessation of alcohol intake, cigarette smoking and parenteral injections of hydroxocobalamin (vitamin B12) weekly. Foods rich in vitamin B complex include meat, liver, yeast, eggs, potatoes, milk, peanut, beans, cereals like corn and millet.

\section{DIABETES}

Compliance to prescribed diet and good glycemic control is important in diabetics. This helps to reduce the progression of diabetic retinopathy and cataracts $^{31,32}$.

Zeaxanthin reduces retinal oxidative damage and production of vascular endothelial growth factor (VEGF) ${ }^{33}$ which is implicated in diabetic retinopathy. Other experimental supplements for diabetic eyes include chromium, high dose vitamin $\mathrm{E}$, magnesium and taurine ${ }^{34}$. 


\section{OBESITY}

Although obesity does not appear to have direct effects on the eye, it is associated with conditions which can adversely affect the eye. Obesity is associated with hypertension, dyslipidemia and impaired glucose tolerance. These conditions can cause central retinal vein occlusion, central retinal artery occlusion, anterior ischemic optic neuropathy ${ }^{37}$. It is also associated with benign intracranial hypertension which causes papilloedema and can lead to secondary optic atrophy ${ }^{38}$.

Vitamin $C$ is helpful in laying down of collagen and healing of the cornea and sclera.

\section{CONCLUSION}

In a nutshell a healthy diet for the eyes includes

- Vitamin A: cod liver oil, liver, carrots, sweet potatoes, palm oil.

- Lutein and zeaxanthin: dark green vegetables, egg yolk, corn, mango.

- spinach, kale, lettuce,

- Vitamin C: oranges, sweet peppers (red or green), kale, strawberries, broccoli, citrus fruits, tomatoes, cherries, grapes.

- Vitamin E: peanuts, almonds, hazelnuts, sunflower seeds.

- Selenium (an antioxidant): yeast, seafood.

- Zinc: oysters, wheat, nuts.

Omega 3 Fatty acids: cold-water fish (salmon, mackerel, trout]

It is recommended that we take five servings of fruits and vegetables every day, two servings of nuts every day and to eat fish at least two days a week for healthy eyes.

\section{REFERENCES}

1. Diet, Nutrition and the Prevention of Chronic Diseases. WHO Technical series: 916. Report of Joint WHO /FAO Expert Consultation. Geneva 2002.

2. Sommer A. Nutritional blindness, xerophthalmia, and keratomalacia. New York: Oxford University Press, 1982.

3. Engelfriet $P$, Hoekstra J, Hoogenveen $R$, Büchner $F$, van Rossum C, Verschuren M. Food and vessels: the importance of a healthy diet to prevent cardiovascular disease. Eur $\mathrm{J}$ Cardiovasc Prev Rehabil. 2009 Jul 9.

4. Waśkiewicz A, Piotrowski W, Sygnowska E, Broda G, Drygas W, Zdrojewski T, Kozakiewicz K, Tykarski A, Biela U. Quality of nutrition and health knowledge in subjects with diagnosed cardio-vascular diseases in the Polish population--National Multicentre Health Survey (WOBASZ).Kardiol Pol. 2008; 66:507-13.

5. Head KA. Natural therapies for ocular disorders, part two: cataracts and glaucoma.Altern Med Rev 2001; 6:141-66.

6. Basic and Clinical Science course. Section 2. AAO 20042005 pg. 363-368.

7. Mucida D, Park $Y$, Cheroutre $H$. From the diet to the nucleus: vitamin $A$ and TGF-beta join efforts at the mucosal interface 
of the intestine. Semin Immunol 2009; 21:14-21.

8. Kanski

J. Clinical
Elsevier
$6^{\text {th }}$

Butterworth-Heinmann edition 2007: 287-8.

9. Gilbert C, HernandezDuran LA, Kotiankar S, McGavin M. Prevention of Childhood Blindness. Authors: International Centre for Eye Health. Published: 1998, (updated 2007).

10.WHO/UNICEF. Indicators for assessing vitamin A deficiency and their application in monitoring and evaluating intervention programmes. Geneva: WHO/NUT/94.1, 1994.

\section{WHO/UNICEF/IVACG Task} Force. Vitamin A supplements: a guide to their use in the treatment and prevention of vitamin A deficiency and xerophthalmia. Geneva: WHO, 1988.

12. Sightsavers International. National Survey provides important new data about blindness in Nigeria. 2008. www.sightsavers.org/.../10380

Nigeria \%20blindness $\% 20$ surv ey.pdf

13. Basic and Clinical Science Course. Section 2. AAO 20042005: pg 345-354

14. Hyman L, Wu SY, Connell AM, Schachat $A$, Nemesure $B$, Hennis A, Leske MC. Prevalence and causes of visual impairment in the Barbados Eye Study.
Ophthalmology.

2001 108:1751-6.

15. Vinson JA. Oxidative stress in cataracts. Pathophysiology. 2006; 13:151-62.

16. Chiu CJ, Milton RC, Gensler G, Taylor A. Dietary carbohydrate intake and glycemic index in relation to cortical and nuclear lens opacities in the AgeRelated Eye Disease Study. Am J Clin Nutr. 2006; 83:1177-84.

17. Lyle BJ, Mares-Perlman JA, Klein BEK, et al. Antioxidant Intake and Risk of Incident AgeRelated Nuclear Cataracts in the Beaver Dam Eye Study. Am J Epidemiol 1999; 149:801-9.

18. Klein BE, Knudtson MD, Lee KE, Reinke JO, Danforth LG, Wealti AM, Moore E, Klein R. Supplements and age-related eye conditions, The Beaver Dam Eye study. Ophthalmology. 2008; 115:1203-8.

19. Jacques PF, Taylor A, Hankinson SE, Willett WC, Mahnken B, Lee $\mathrm{K}$ et al. Am J Clin Nutr. 1997; 66:739-40.

20. Cumming RG, Mitchell $P$, Smith W. Diet and cataract: the Blue Mountains Eye Study. Ophthalmology 2000; 107:4506.

21. Leske MC, Chylack LT Jr, Wu SY. The Lens Opacities CaseControl Study. Risk factors for cataract. Arch Ophthalmol. 1991; 109:1635-6.

22. Chiu CJ, Klein R, Milton RC, Gensler G, Taylor A. Does 
eating particular diets alter risk of age-related macular degeneration in users of the age-related eye disease study supplements? $\mathrm{Br} \mathrm{J}$ Ophthalmol. 2009 Jun 12.

23. Coleman $\mathrm{H}$, Chew E. Nutritional supplementation in age-related macular degeneration. Curr Opin Ophthalmol. 2007; 18(3):220-3.

24. A randomized, placebocontrolled, clinical trial of highdose supplementation with vitamins $C$ and $E$, beta carotene, and zinc for agerelated macular degeneration and vision loss: AREDS report no. 8. Age-Related Eye Disease Study Research Group. Arch Ophthalmol. 2001; 119(10): 1417-36.

25. Bartlett H, Eperjesi F. Agerelated macular degeneration and nutritional supplementation: a review of randomised controlled trials. Ophthalmic Physiol Opt. 2003; S23:383-99.

26. Veach J. Functional dichotomy: glutathione and vitamin $\mathrm{E}$ in homeostasis relevant to primary open-angle glaucoma. $\mathrm{Br} J$ Nutr. 2004; 91(6):809-29.

27. Aleksidze AT, Beradze IN, Golovachev O. Effect of the ascorbic acid of the aqueous humor on the lipid peroxidation process in the eye in primary open-angle glaucoma.Ofthalmol Zh1989; (2):114-6.

28. Chung HS, Harris A, Kristinsson JK, Ciulla TA, Kagemann C, Ritch R. Ginkgo biloba extract increases ocular blood flow velocity. J Ocul Pharmacol Ther 1999; 15(3):233-40.

29. Khurana AK. Comprehensive Ophthalmology. $4^{\text {th }}$ edition. New Age International Publishers. New Delhi 2007: pg 296-97.

30. Osuntokun BO, Aladetoyinbo A, Bademosi O. Vitamin B nutrition in the Nigerian tropical ataxic neuropathy. J Neurol Neurosurg Psychiatry. 1985; 48: 154-6.

31. Swamy-Mruthinti S, Shaw SM, Zhao HR, Green K, Abraham EC. Evidence of a glycemic threshold for the development of cataracts in diabetic rats. Curr Eye Res. 1999; 18:423425.

32. Orasanu G, Plutzky J. The pathologic continuum of diabetic vascular disease. J Am Coll Cardiol. 2009; 53(5 Suppl):S3542.

33. Kowluru RA, Menon B, Gierhart DL. Beneficial effect of zeaxanthin on retinal metabolic abnormalities in diabetic rats. Invest Ophthalmol Vis Sci. 2008; 49:1645-51.

34. McCarty MF. Glucomannan minimizes the postprandial insulin surge: a potential adjuvant for hepatothermic therapy. Med Hypotheses. 2002; 58:487-90

35. Khurana AK. Comprehensive Ophthalmology. $4^{\text {th }}$ edition. New Age International Publishers. New Delhi. Pg 434.

36. Sandford-Smith J. Eye Diseases in Hot Climates. $4^{\text {th }}$ edition.Elsevier. pg 211. 
37. Nguyen TT, Wang JJ, Islam FM, Mitchell P, Tapp RJ, Zimmet $\mathrm{PZe}$ et al. Retinal arteriolar narrowing predicts incidence of diabetes: the Australian Diabetes, Obesity and Lifestyle (AusDiab) Study. Diabetes. 2008; 57(3):536-9.
38. Hannerz J, Ericson K. The relationship between idiopathic intracranial hypertension and obesity. Headache. 2009; 49(2):178-84. 